\title{
PRODUCT PORTFOLIO MANAGEMENT: AN IMPORTANT BUSINESS STRATEGY
}

\author{
Mishelle DOORASAMY \\ Durban University of Technology, Department of Financial Accounting, Durban, South Africa \\ e-mail: mishelled@dut.ac.za
}

\begin{abstract}
The aim of this article is to provide reader with a comprehensive insight on the theories, empirical findings and models of Product Portfolio Management (PPM) during new product development. This article will allow for an in-depth theoretical approach on PPM and demonstrate to managers the importance of adopting PPM as business strategy during decision making. The objective of this paper is to present a literature review of models, theories, approaches and findings on the relationship between Product Portfolio Management and new product development. Relevant statistical trends, historical developments, published opinion of major writers in this field will be presented to provide concrete evidence of the problem being discussed.
\end{abstract}

Keywords: product portfolio management, new product development, business strategy, decision making.

\section{$1 \quad$ Introduction}

Cooper (2012:3) states that "Twenty five years of research into why new products succeed, why they fail and what distinguishes winning businesses and are we any further ahead? Some pundits say no! Today's new product project teams and leaders seem to fall into the same trap as their predecessors did back in the 1970s". The current state of product innovation is that it does not happen as well as it should because critical success factors are absent from the typical new product development project. Buyers have become increasingly demanding and no longer see a contradiction between product innovation and development and falling prices. For example, mobile phone manufacturer, Nokia and Sony Erickson offer superior products every year at similar or below previous prices. "Given that most theories of business eventually become obsolete, the key competency for any organization that wants to survive in the market is the ability to innovate" (West, Ford and Ibrahim 2010:264).

Product Portfolio Management gives organisations the ability to obtain the utmost value from their product portfolios by applying portfolio management principles to the product development process (Planview 2012). AberdeenGroup (2006:3) states that throughout the new product development process, companies should focus on the value being generated for the company.
Continued evaluation of the product development project can help companies assess the probability of achieving the expected value from the project and assist in decision making.

\section{Significance of the study}

One opportunity for improvement is to address "the product portfolio value gap." The value of executing the right product portfolio and realizing its full potential available is often neglected by companies. As a result inadequately defined portfolios, and poor project execution drain value from projects. (AberdeenGroup 2006:3). Cooper (2012:3) states that recent studies reveal that the art of product development has not shown much improvement. The voice of the customer is still missing, solid up front research is not done and that many products enter the development phase lacking clear definition. Moreover, there is major challenge of economic instability. Business executive, Roux (2011:1) stated that FMCG market volumes contract as inflation increases. Competition is fierce as local and multinational competitors and retailers enter the market. The situation becomes critical as leading companies like Unilever are accepting lower margins in exchange for growth. As a result, sensitive consumers push margin downwards (Euromonitor, Nestle', Unilever 2010). 
Evans and Lindsay (2008:12) found that design quality and innovation will be of much significance to deal with faster rates of change, shorter life cycles and rising consumer sophistication. It has been estimated that almost 80 percent of all new products fail and the strategic problem is that if a product fails, the company tied to this product will also be negatively affected by the failure. The failed brand would tarnish the overall brand reputation, which could be disastrous for the company involved.

\section{$3 \quad$ Literature review}

- Product Portfolio Management best practice

Portfolio management best practice are financial (maximize return), competitive advantage and efficient allocation of resources (Cooper, Edgett and Kleinschmidt 2012).

- New Product Development best practice

A study on NPD best practice by Kahn, Barczak, Ledwith, Perks and Nicholas (2012:180-192) reported that best practice would be those new product development practices that promotes greater success in developing and launching new product and services. They characterized NPD practice across seven dimensions i.e., strategy, process, research, project climate, company culture, metric and performance measurement and commercialization. The research was conducted on NPD practitioners of three different countries. Their findings were that there was a lack of understanding and implementation of the best practice elements of climate, culture and especially metrics.

Duncan (2012:2) helped companies implement innovation governance. He reported findings on best practices of innovation and product management as follows: focus on business processes, plan implementation phase, avoid complexity, address decision making first, tasks second and launch is when the most important works begins.

It can be concluded from the review above that different organizations view best practice differently. Both Kahn et al (2012:180-192) as well as Duncan (2012:2) have made valuable contributions towards benchmarking best practice. However there is no "one size fits all".

- Best Practice models for New Product development process and Product Portfolio Management.

Fig. 1 represents a bubble diagram of NPD projects. The size of each bubble shows the annual resources spent on each company division and the shading is the product line.

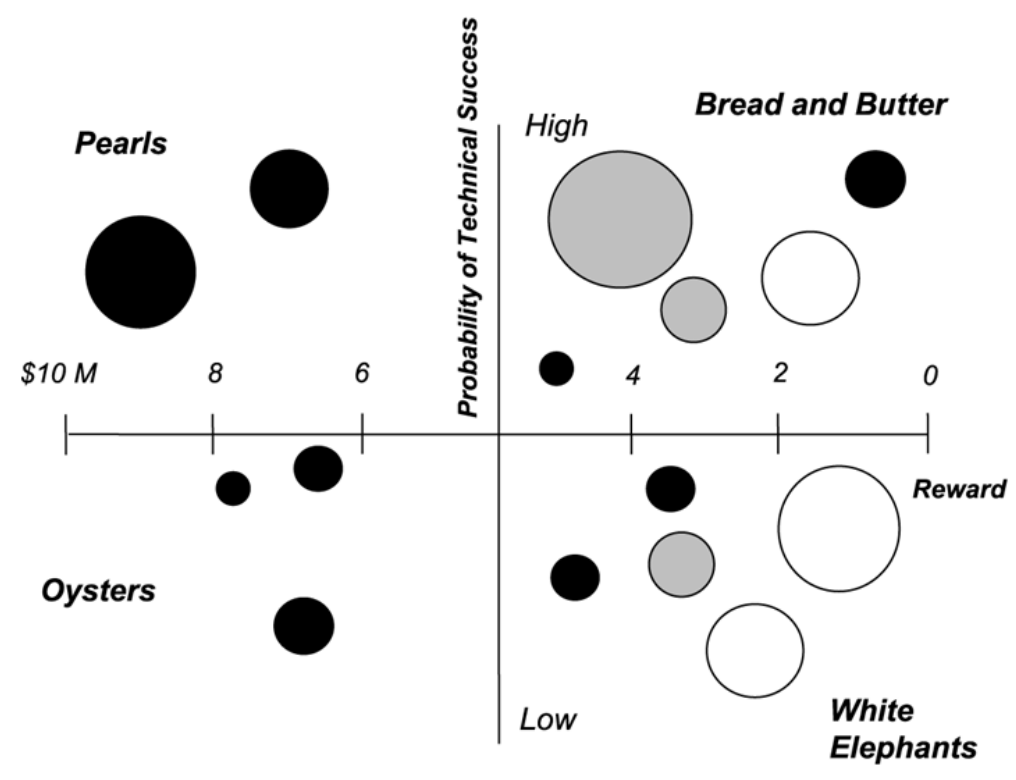

Figure 1. Bubble diagram of a portfolio of new product projects (source: Cooper 1997:24 as cited by Cooper, Edgett and Kleinschmidt 2012) 
Fig. 2 is the stage gate process for NPD. The best practices for product development should be sup- ported by the implementation of this approach (Cooper 2012).

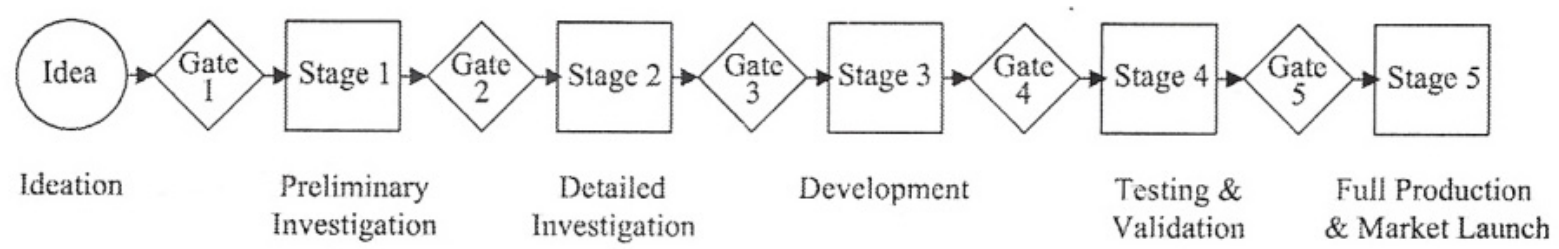

Figure 2. A generic stage gate process for new product

(source: Cooper 1993 as cited by Cooper 2012)

- Empirical findings, moels/theories/approaches on Product Portfolio Management and New Product development

Empirical research findings by Cooper, Edgett and Kleinschmidt (2007:1-2) were that there are three key factors in developing new product, a high quality new product process, a clear and well communicated new product strategy for the business and adequate resources for new products. Hill (2009:132) states that through the interaction of scientific research demand conditions and competitive conditions stimulate ideas for new products. He also found that rate of new product development is greater in countries where more money is spent on basic and applied research and development, demand is strong, consumers are affluent and competitions intense. Contrary to Hill, a totally new approach by Pitta (2012:35-46) based on recent research on transforming the nature and scope of new product development. This is reflected in model 1 below.

\section{Model 1}

The introduction of "Blue Oceans-Red Oceans Strategy" is a perspective that offers the hope of escaping destructive competitive market space for a new environment with more opportunities.

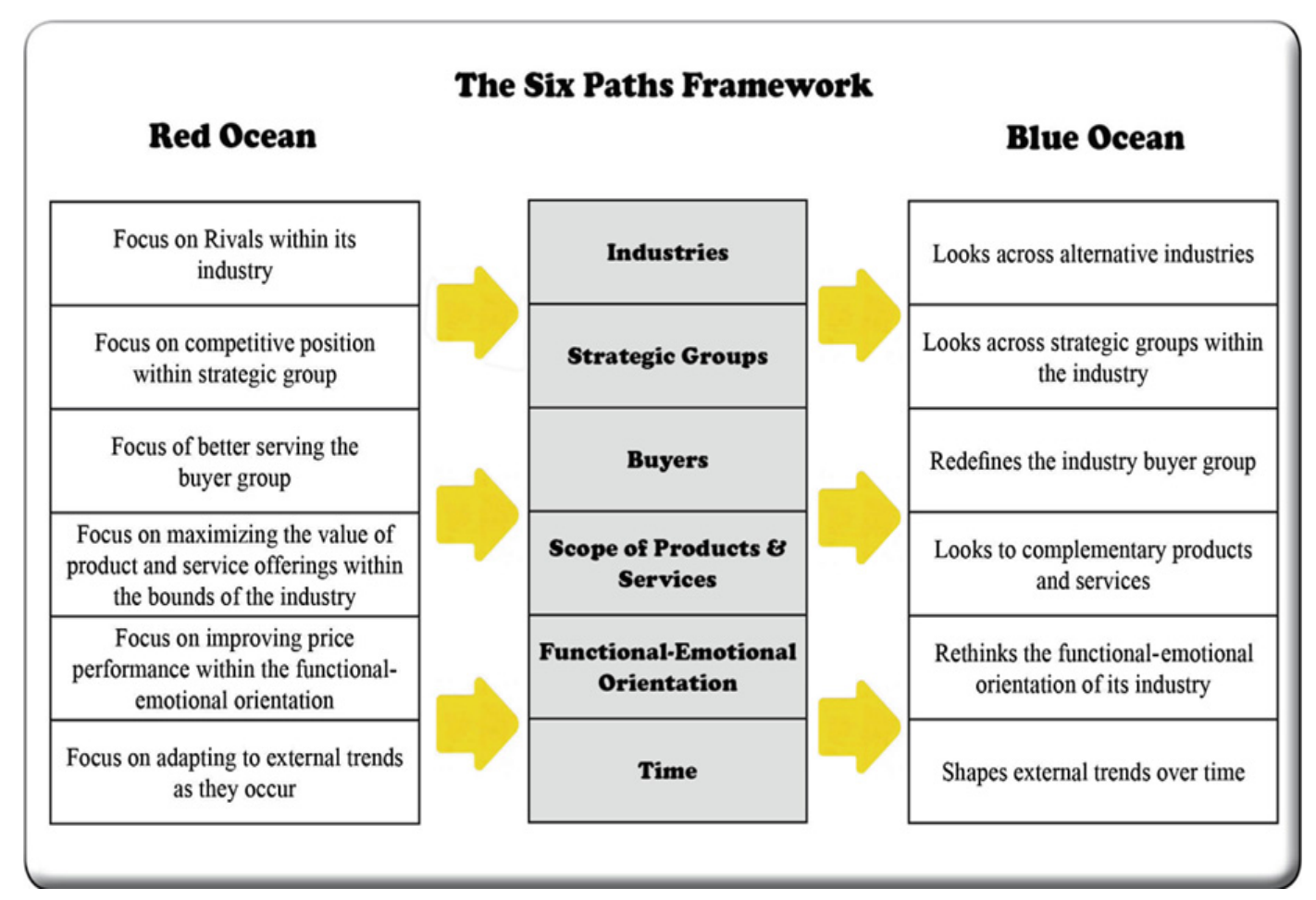

Figure 3. Six paths frameworks

(source: Kim and Mauborgne 2007, as cited by Pitta 2012:40) 
Fig. 3 indicates the blue ocean strategy tool to create market space.

The finding of this research was that companies were able to gain greater competitive advantage by competing in uncluttered market and increase their chances of successful new products developments (Pitta 2012:41)

The findings of Cooper (2012:9) are somewhat different from Hill (2009:132). Cooper focuses more on NPD processes whereas Hill views market research as the driving force of NPD. A contradicting view point to Cooper (2012:9), which indicated that excellence in NPD process is the primary driver of NPD success. Nicholas (2011:227-251) disagrees with Cooper. He conducted a research to identify the gap between what researchers and practitioners understand to be NPD best practice. He found that strategy is the most important best practice for NPD. Recent research by Aberdeen Group adds new dimension to the NPD process.

Model 2 below highlights best practices in NPD processes, cross functional project teams that has total support from top management in striving to achieve "speed to market".

Model 2: New product development process

Fig. 4 explains the key to competitive advantage is based on two factors: strategic impact and efficient use of resources (New product development process components 2012:1-2).

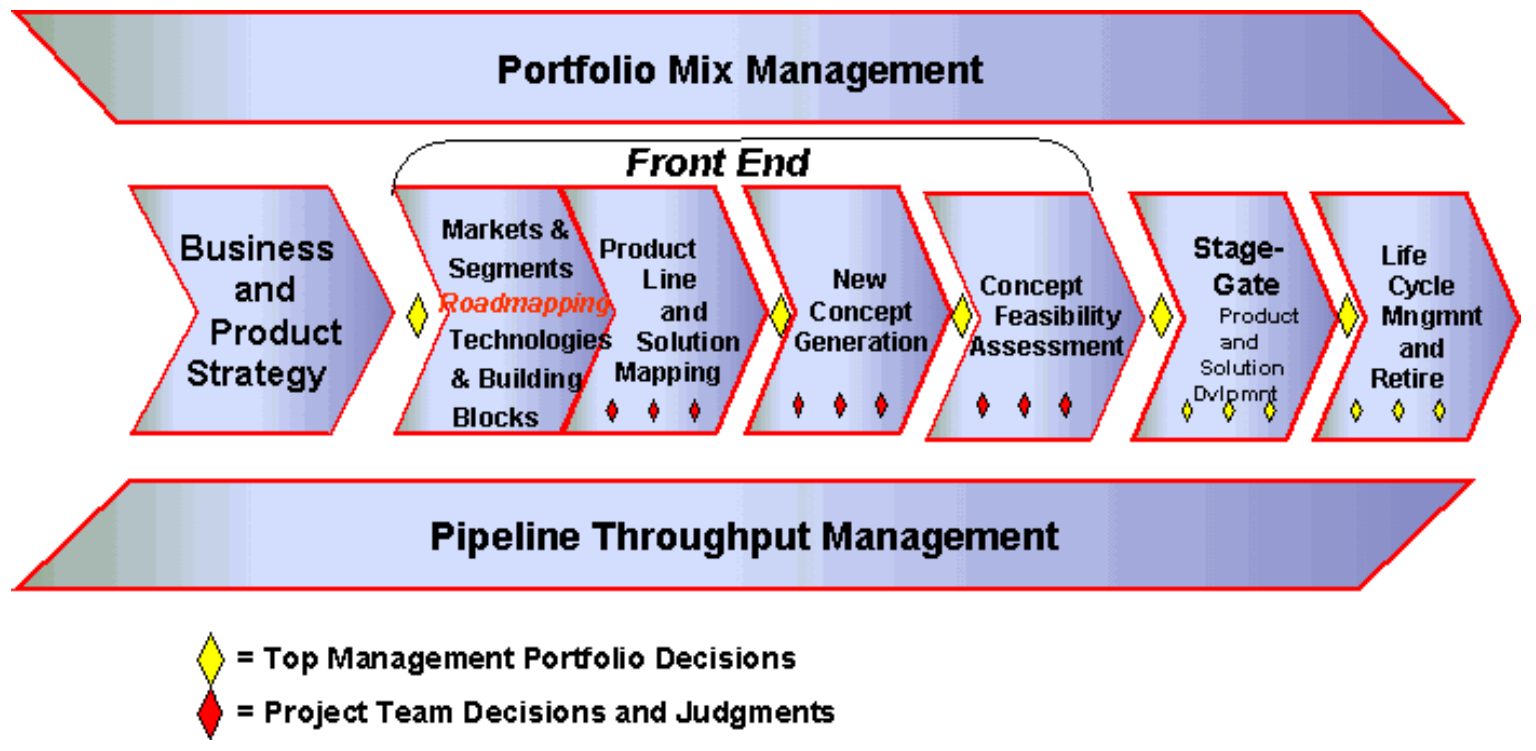

Figure 4. Best practices in NPD processes. "Speed to market" (source: The Adept group Ltd 2012:1)

He argues that the survey conducted indicated that $75 \%$ of all companies view collaboration and project management are very important to the process $(\mathrm{Ab}-$ erdeen Group 2006:3).

The Product Development Management Association states that the best way to manage one's NPD projects and product portfolios is as process driven hierarchies and stresses the importance of active involvement by top management in defining portfolio strategy (Schmidt, Sarangee and Montoya 2009:520-535).
Product portfolio management (PPM) in the past was focused primary on fast moving consumer goods (Brown 2010:3-8). Research conducted by Brown (2010:3-8) on how PPM can be more closely tied to engineering projects. He looked at closing the gap between product planning and the design and development. He talks about "exnovation" which is a practice by organizations to adjusting their portfolio by getting rid of poor performance projects and adding a different set of products to increase the profitability of the company (Brown 2010:3-8). 


\section{Shifting Focus of Portfolio Management}

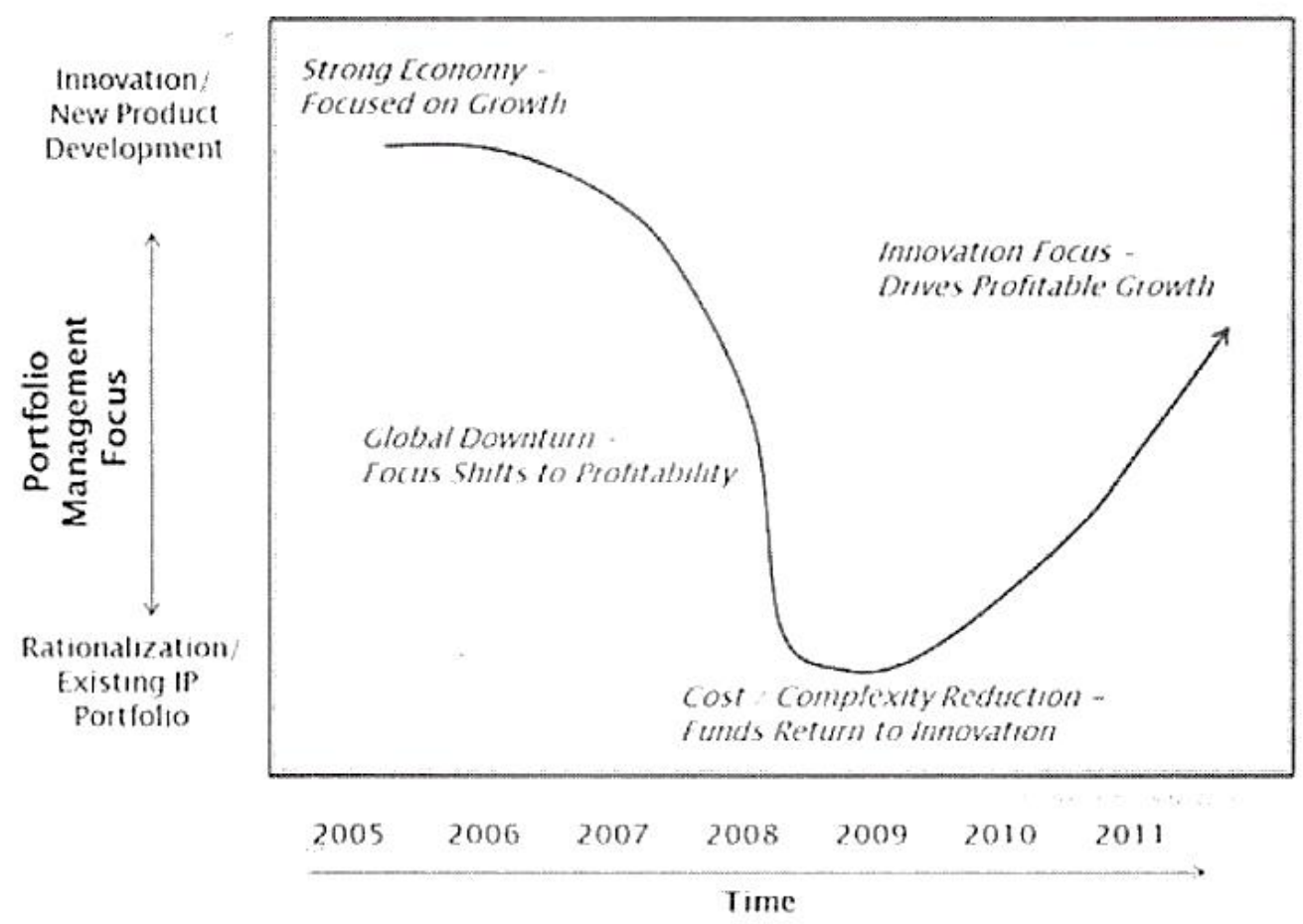

Figure 5. Product Portfolio Shift

(source: Jim Brown 2010:3)

Fig. 5 depicts the process of the "Product Portfolio Shift" and indicates the process of shifting the focus of portfolio management.

Research findings on the reasons behind the poor performance of new product development are due to product portfolio management being disengaged from the company's vision.

An article on value innovation portfolio management (2006:1) suggested that a customer centric portfolio management is what managers should strive for. Similarly a survey was conducted on 64 senior project managers to assess their views on PPM.

The findings were that the biggest challenge was the lack of executive support (CBP survey of project portfolio management practices 2010:1). These finding are an agreement with the Aberdeen Group and also the Product Development Management Association.
However, Cooper (2012:9) argues that the reason for companies not achieving success in due to poor NPD processes.

Model 3 below reflects the challenges faced by organizations in NPD processes.

\section{Model 3}

Fig. 6 above is a visual representation of how the problems encountered by organizations in the new products development process feed each other.

He suggested that intensive market research and reengineering the entire NPD process is the solution.

A study conducted by Cooper, Edgett and Kleinschmidt (2012:3) states that there are two ways for a business to succeed at new products, i.e., doing projects right and doing the right projects.

Model 4 below represents the best practices for PPM is doing the right projects the right way. 


\section{How the Problems Feed Each Other - A Downward Spiral}

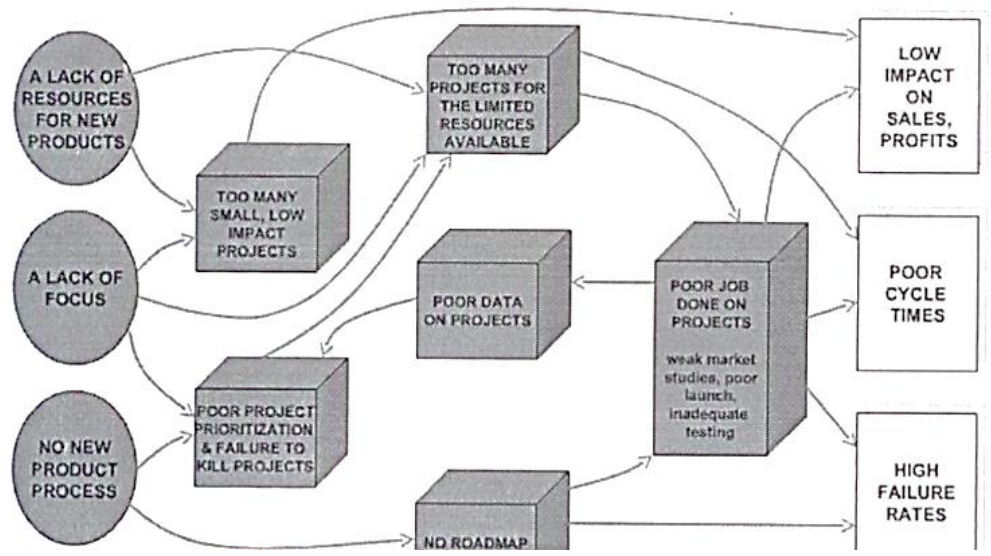

Figure 6. Challenges faced by organizations in new product development process (source: Iainsanders 2009:3)

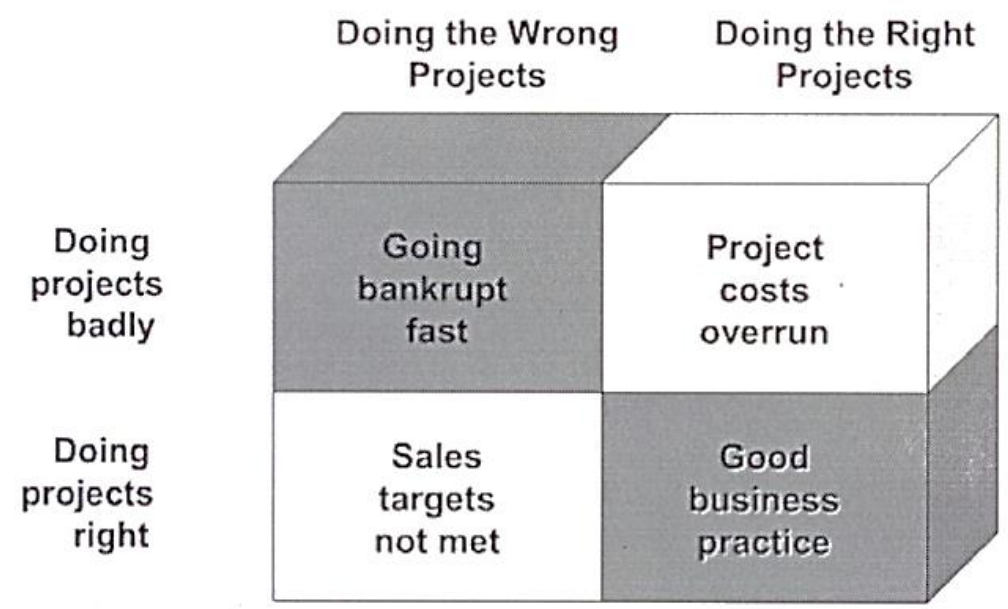

Figure 7. Representation of best practice for PPM is doing the right projects the right way (source: Iainsanders 2009:4)

Model 4: Product portfolio management

Fig. 7 above indicates the impact of decision making in product portfolio management.

The empirical evidence supports the critical role of senior management in PPM. Results from a study, examining the consequences of poor portfolio management practices found that the portfolio bubble diagram as most suitable for achieving a balance of projects (Cooper, Edgett and Kleinschmidt 2007:19). According to modern portfolio theory, a company can reduce the risk of their investments by creating a diversified portfolio so that some investments may produce strong returns during poor economic climate (Hanford 2007:1). Kirkpatrick
(2007:7) is in disagreement with Cooper in that he feels that market research is important at every stage of development. He feels that the company goes beyond the product created.

A further study was conducted in a manufacturing industry where portfolio management was introduced as a new organization practices. Augusto, Miguel (2008:10-23) found that PPM helped raise the profile of new product development system and can be effective if it is aligned with company strategy. However future research is needed to develop a framework for better integration between the PPM process and NPD process. 
A critical analysis of the various literature reviews and empirical evidence reveal that top management involvement and support, consumers, resource allocation are all essential ingredients to successful product portfolio management which will increase the success rate of new product development process and lead to improved organizational performance.

\section{Conclusions from literature review}

The objective of this study was to present a literature review of models, theories, approaches and findings on the relationship between product portfolio management and new product development.

Evaluation of the literature review suggests that new products can allow companies to change strategic direction, prevent companies from becoming stagnant, improves competition and fills a niche in the market place. New product development is seen as a four step process: create, assess, develop and pursue. For almost 20 years researchers have focused on determining principles and tools to increase the efficiency of new product development (NPD) processes. However, the success rate of new products in the market still remains low. It is described like milk and cream, where the best new products opportunities rise to the top of the list whilst the balance is discarded.

New product introductions performance in the market depends on management ability to anticipate the critical factors of success or failure. Research has shown that different organizations view NPD best practice differently. NPD best practice has been characterized across seven dimensions, i.e., strategy, process, research, project climate, company culture, metric and performance measurement and commercialization.

Others view best products to be consumer oriented and that products should be conceived and designed to address the needs of real people. A significant relationship exists between NPD and product portfolio management. NPD poor performance has been directly or indirectly attributed to poor product portfolio management.

Portfolio management best practices maximize return, competitive advantage and efficient allocation of resources. If NDP projects have failed to achieve their objectives, it does indicate a flaw in the product portfolio management process implemented by the organization.

Management ability to identify the best projects that align with business strategy in order to efficiently allocate scarce resources is critical to an organization's success and NPD performance. The bubble diagram (Fig. 1) has been identified as an effective tool for resource allocation. NPD success depends largely on two things: doing projects right and doing the right projects. Market research and testing should be conducted at every stage of the development of the project in order to make go/kill decisions. If projects that are unlikely to succeed can be identified earlier in the development phase before further investments, it could save the company from incurring huge losses due to poor project selection.

The findings indicate that lack of executive support and insufficient upfront information for decision making are some of the biggest challenges faced by organizations.

It has been established from the literature review that some of the top performers in NDP choose projects that are aligned with company strategy rather than placing too much emphasis on financial returns. Based on the evidence from the study, it can be concluded that an organization's performance can be improved by achieving a well-balanced, high value diversified portfolio.

Top management involvement and support, consumers, efficient resource allocations are all essential ingredients to successful product portfolio management which will, in turn, improve NDP performance in organizations.

\section{$5 \quad$ Recommendations}

In light of the ongoing challenges faced by management: inability to properly value product opportunity and align resources to appropriate projects for their portfolios in order to achieve success in NPD projects, and based on the literature accumulated, benchmarks for NPD best practice as well as product portfolio management best practice are proposed. 
Product portfolio management techniques are recommended to address the concerns of diminishing product portfolio relevance and loss of competitive advantage of the company in this study.

\section{Reference}

[1] AberdeenGroup (2006) - The product portfolio management benchmark report (online).

URL:http//emeraldinsight.com (accessed $29 \mathrm{Fe}-$ bruary 2012).

[2] Augusto P., Miguel C. (2008) - Portfolio management and new product development implementation: A case study in a manufacturing firm. International journal of quality and reliability management (online), 25(1):10-23.

URL:http//emeraldinsight.com/newproductdevel opment (accessed 28 February 2012).

[3] Brown J. (2010) - Are there best practices for product portfolio management / clarity on plm (online). URL:http://tech-clarity.com/clarity on $\mathrm{plm} / 2011 /$ ppmbest practice (accessed 4 February 2012).

[4] CBP Surveys of project Portfolio management practices(online). (2010). Available:

URL:http//prioritysystem.com/survey.html (accessed 18 March 2012).

[5] Cooper G.R., Edgett J.S., Kleinschmidt J.E. (2012) - Portfolio Management: Fundamentals for new product success. Journal of product innovation best practices series (online), 1-4. Available URL:http://stagegate.com (accessed 22 March 2012).

[6] Cooper G.R. (2012) - From experience the invisible success factors in product innovation (online). Available URL:http://stage.com (accessed 22 March 2012).

[7] Cooper G.R. (2012) - From experience the invisible success factors in product innovation (online). Available URL:http://stage.com (accessed 22 March 2012).

[8] Cooper G.R., Edgett J.S., Kleinschmidt J.E. (2007) - Portfolio management for new product development. Results of an industry practices study. Journal of product innovation best practices series (online), 31 (4): 1-20. Available
URL:http://stagegate.com (accessed 28 February 2012).

[9] Duncan K. (2012) - What works: 6 best practices of innovation and product portfolio management. Sopheon:news and events (online). Available URL: http:// sopheon.com /newsevents /inknowvations newsletter (accessed 24 March 2012).

[10] Hanford F.M. (2007) - Organizational capability and portfolio management adaption (online). Available

URL:http//ibm.com/developerworks/rational/libr ary/ (accessed 18 March 2012).

[11] Hill W.L.C. (2009) - International business competing in the global market place. Seventh edition. New York : McGraw-Hill/ Irwin.

[12] Kahn B.K., Barczak, G., Nicholas, J., Ledwith, A., Perks, H. (2012) - An examination of new product development best practice. Journal of product innovation management (online), 29(2): 180-192. Available:

URL:http://onlinelibrary.wiley.com/doi/10.111/j 1540-5885 (accessed 29 March 2012).

[13] Kirkpatrick P. (2007) - New product development - From idea to market (online). Available URL:http//davidkirkpatrick.hubpages.com/hub/n ew-productdevelopment (accessed 24 March 2012).

[14] Nicholas J. (2011) - New product development best practice in SME and large organizations : theory vs practice. European journal of innovation management (online), 17 (2):227-251. Available URL: http://emeraldinsight.com/14601060.htm (accessed 23 March 2012).

[15] Pitta D., Pita E. (2012) - Transforming the nature and scope of new product development (online), Journal of product and brand management. 21(1): 35-46. Available

URL:http://dxdoi.org/10.1108/10310421211203 097 (accessed 30 March 2012).

[16] Schmidt B.J., Sarangee R.K., Montoya M.M. (2009) - Exploring new product development project review practices. Journal of product innovation management (online), 26(5): 520-535. Available URL:http://mendeley.com /research /exploring -new -product -development-projectreview (accessed on 22 March 2012). 